\title{
Effect of Stem Bark Hydroalcoholic Extract of Cocoa (T. Cacao) on Liver Function of Wistar Albino Rats Induced with Anaemia
}

\section{${ }^{1}$ GEORGE-OPUDA, IM; ${ }^{* 2}$ ADEGOKE, OA; ${ }^{2,3}$ OLUWATAYO, OB; ${ }^{4}$ ODEGHE, OB; ${ }^{2}$ NDIBE, J}

\author{
${ }^{I}$ Department of Medical Laboratory Science, Rivers State University, Port Harcourt, Nigeria \\ ${ }^{* 2}$ Department of Medical Laboratory Science, ${ }^{1}$ Department of Physiology, Madonna University, Elele, Nigeria. \\ ${ }^{3}$ Federal College of Veterinary and Medical Laboratory Technology, Vom, Nigeria \\ ${ }^{4}$ Department of Biochemistry, Faculty of Science, Madonna University, Elele, Nigeria \\ *Corresponding Author Email bayoadeghq@yahoo.com; Tel: +2348037103687 \\ Email of other Authors: tunduntayo91@yahoo.com; bensandym@yahoo.com
}

\begin{abstract}
The study investigated the effect of stem bark hydroalcoholic extract of cocoa (Theobroma cacao) on liver function of phenlyhydrazine (PHZ)-induced forty anaemic (treated) and normal albino rats divided into 8 groups of five rats each in the study. The activities of marker enzymes such as aspartate amino transferase (AST), alanine amino transferase (ALT) and alkaline phosphatase (ALP), were assayed. In addition serum total protein, total bilirubin, albumin were determined. There was a significantly $(p<0.05)$ decrease in AST of anaemic not treated rats compared to normal control rats with the exception of serum total protein, total bilirubin, direct bilirubin, albumin, ALT and ALP where no significant $(p>0.005)$ change was recorded. In the group (anaemic rats) treated with bark extract of Theobroma cacao at the doses of 100,200 , and $500 \mathrm{mg} / \mathrm{kg}$, AST was significantly $(p<0.05)$ reduced while there was significant $(p>0.05)$ increase in serum total protein, total bilirubin, albumin, ALT and ALP. In the group (non anaemic rats) treated with graded doses of the extract $200 \mathrm{mg}, 500 \mathrm{mg}$ and $1000 \mathrm{mg}$, there was a significant $(\mathrm{p}<0.05)$ of total bilirubin diect bilirubin, and AST while no significant $(p>0.05)$ change was recorded. The study illustrate that the bark extract of Theobroma cacao possess antioxidant and membrane permeability properties. Dose of Theobroma cacao at $500 \mathrm{mg}$ does not have antianaemic potentials.
\end{abstract}

\section{DOI:https://dx.doi.org/10.4314/jasem.v25i9.25}

Copyright: Copyright $(02021$ George-Opuda et al. This is an open access article distributed under the Creative Commons Attribution License (CCL), which permits unrestricted use, distribution, and reproduction in any medium, provided the original work is properly cited.

Dates: Received: 09 May 2021; Revised: 12 August 2021; Accepted: 12 September 2021

Keywords: Theobroma cacao, Anaemic, Phenylhydrazine, Liver

Cocoa (Theobroma cacao) is a major economic tree crop in Nigeria (Alamu, 2013). T. cacao grows in the subtropical areas of the world. Although it grows widely from thesoutheastern Mexico to the Amazon basin, two thirds of the world's production comesfrom four West African countries, the Ivory Coast, Ghana, Nigeria and Cameroon.Ivory Coast is the world's largest exporter of cocoa (Agarwal, 2013). Cocoa is rich in flavonoids which protect against cardiovascular diseases through their antioxidant, antiplatelet, and anti-inflammatory effects. Flavonoids may also lower blood pressure, increase high density lipoprotein cholesterol, positively modify insulin sensitivity and improve endothelial function (Agarwal, 2013). The qualitative phytochemical analysis of aqueous, methanol, ethanol and acetone extracts of Theobroma cacao revealed the presence of carbohydrates, saponins, steroids, tannins, flavonoids, polyphenol and alkaloids in all four extracts, with flavonoids, tannins and steroids existing in trace amount in some extract. Cocoa and cocoa derivatives are recognized as major dietary source of antioxidants because of their high phenolic. The role of liver in metabolic conversion is due to its susceptibility to chemical injury (Zimmerman, 1974). Liver enzymes such as lactate dehydrogenase (LDH), glutamic oxaloacetic acid transaminase (GOT), glutamic pyruvic acid transaminase (GPT), alkaline phosphatase and gamma glutamyltranspeptidase (GGT) are considered to be biochemical markers for assessing liver function. Elevation of alanine aminotransferase (ALT or GPT) activity appears to reflect hepatic disease and it is more specific for hepatic disease than aspartate aminotransferase (AST or GOT) because of the biological location of the enzymes. However the elevation of AST and ALT along with the alkaline phosphates (ALKPHOS) activity may reflect some inflammatory disease or injury to the liver (Dede, et al., 2001). The objective of this study is to investigate the effect of stem bark hydroalcoholic extract of cocoa (Theobroma cacao) on liver function of 
phenylhydrazine (PHZ) induced anaemic (treated) and normal albino rats.

\section{MATERIALS AND METHOD}

Plant Material: Mature bark of Theobroma cacao were harvested from local farms in Njaba Local Government Area of Imo State, Nigeria and identified at the department of Pharmacognosy of Madonna University.

Animals: Forty Wistar albino rats were used for the biochemical studies. Wistar albino rats were purchased from the Animal House of the Faculty of Biological Sciences, University of Nigeria, Nsukka. The rats were fed rat pellets (Grand Cereals and Oil Mills Ltd, Jos, Nigeria) and water ad libitum.

Preparation of plant material: The stem bark of $T$. cacao (TBC) were removed from the cacao tree, and blanched immediately for 5 minutes at a temperature of $95^{\circ} \mathrm{C}$, and air dried under a shed. The preparation of the stem bark of Theobroma cacao was as described by Schinella et al., (2010). A known weight, $500 \mathrm{~g}$ of the sterm bark was soaked in petroleum ether for three days for the purpose of defatting. The mixture was subsequently filtered using a muslin cloth. The residue was air-dried and extracted using a magnetic stirrer in hydroalcohol solvent of $70 \%$ ethanol for two hours. It was subsequently filtered using a muslin cloth and the solution was further filtered with Whatman no. 4 filter paper and the filtrate was concentrated to a semi-solid residue in a water bath at $600 \mathrm{C}$.

Determination of stem bark Content: The total stem bark content in T. cacao was determined using FolinCiocalteu's Reagent as described by Velioglu et al., (1998) with slight modifications. The extract was prepared at a concentration of $1 \mathrm{mg} / \mathrm{ml}$ using ethanol. A measured volume, $100 \mu \mathrm{l}$, of the sample was mixed with $750 \mu \mathrm{l}$ of Folin-Ciocalteu's Reagent (previously diluted 10-fold with distilled water) and allowed to stand for 5 minutes at a temperature of $25^{\circ} \mathrm{C} ; \mathrm{Na}_{2} \mathrm{CO}_{3}$ $(0.57 \mathrm{M})$ solution $(750 \mu \mathrm{l})$ was added to the mixture. After 90 minutes, the absorbance was measured using JENWAY 640 UV/VIS Spectrophotometer (Beckman/Instruments Inc., Huston Texas) at $725 \mathrm{~nm}$. Results were expressed as gallic acid equivalents (GAE) in milligram per $100 \mathrm{~g}$ dry weight of sample. The range of the calibration curve was from 0.01-0.1 $\mathrm{mg} / \mathrm{ml}$ with $\mathrm{R} 2=0.9588$.

Preparation of Drug Solutions: Diphenylhydrazine used as the standard drug was weighed and dissolved in appropriate volume of distilled water. All solutions were kept in tightly closed sterile bottles and were made use of on the same day. Leftovers were discarded.

Induction of anaemia: Anaemia was induced by intraperitoneal injection of diphenylhydazine( $60 \mathrm{mg} / \mathrm{kg}$ body weight b.w), dissolved in physiological saline, for 2 consecutive days in accordance with the methods of Rona et al. (1959) and Seth et al.' (1998). Anaemia was allowed to establish in 24 hours after the second induction. Packed cell volume $<35 \%$ was considered as an index for anaemia

Experimental Design: Forty Wistar rats housed together and fed normal rat feed and water ad libitum under hygienic condition for a period of 40days were randomly divided into 8 groups of 4 rats. The group 1 was given rat diets and water adlibitum to serve as control while Group 2 was given di phenyl hydrazine (PHZ) to induce anaemia. Group 3 was given PHZ to induced anaemia and administered with $100 \mathrm{mg} / \mathrm{kg}$ b.w of TBC, Group 4 was given PHZ to induced anaemia and administered with $200 \mathrm{mg} / \mathrm{kg}$ b.w of TBC while Group 5 was given PHZ to induced anaemia and administered with $500 \mathrm{mg} / \mathrm{kg}$ b.w of TBC. Group 6 albino rats were treated with $200 \mathrm{mg} / \mathrm{kg}$ b.w of TBC, Group 7 albino rats were treated with $500 \mathrm{mg} / \mathrm{kg}$ b.w of TBC while Group 8 albino rats were treated with $1000 \mathrm{mg} / \mathrm{kg} \mathrm{b}$.w of TBC respectively for 14 days. The route of administration of the bark extract of cacao was by oral intubation. At the end of treatment, the animals were then sacrificed. Blood were collected into sample bottles from the heart. The animals were sacrificed by medial decapitation along the stomach and blood was collected from the heart, transferred to plain test tubes, allowed to clot and subsequently centrifuged to obtain the serum component which was used for further biochemical analysis.

Biochemical assay: Determination of ALT and AST was done by monitoring the concentrations of pyruvate hydrazone formed with 2, 4 dinitrophenylhydrazine. Five hundred microlitre $(0.5 \mathrm{ml})$ of buffer solution was dispensed into test tubes labeled blank, sample, control blank and control respectively for AST and ALT respectively. One hundred microlitre $(0.1 \mathrm{ml})$ of sample and control was dispensed into their respective test tubes. All the tubes were incubated at $37^{\circ} \mathrm{C}$ for 30 minutes. Five hundred microlitre $(0.5 \mathrm{ml})$ of 2,4 dinitrophenylhydrazine was dispensed into all test tubes. One hundred microlitre $(0.1 \mathrm{ml})$ of sample and control was dispensed into their respective blank test tube. The contents of each test tube was mixed and allowed to stand for 20 minutes at $25^{\circ} \mathrm{C}$. $5 \mathrm{ml}$ of $0.4 \mathrm{~N}$ sodium hydroxide was added to each tube, mixed and read at $550 \mathrm{~nm}$ against the respective blank prepared. The activity of the 
unknown was extrapolated from the calibration curve already prepared (Reitman, and Frankel, 1957). Alkaline Phosphatase activity was done by Phenolphthalein Monophosphate method (Babson et al., 1966). The test tubes were respectively labeled sample, standard and control. One millilitre $(1.0 \mathrm{ml})$ of distilled water was pipetted into each tube followed by a drop of the substrate into each test tube. All the test tubes were incubated at $37^{\circ} \mathrm{C}$ for 5 minutes. Ten microlitre $(0.1 \mathrm{ml})$ of sample, standard and control were dispensed into their respective test tubes. The test tubes were incubated at $37^{\circ} \mathrm{C}$ for 20 minutes. Five milliliter $(5 \mathrm{ml})$ of colour developer was added to each test tube, mixed, and read at 550nm using water as blank. The Alkaline Phosphatase activity of sample was calculated as shown in equation 1 .

$$
A P(U / I)=\frac{A T}{A S} x C S
$$

Where AP = Alkaline Phosphatase; AT=Absorbance of Test; AS=Absorbance of standard, $\mathrm{CS}=$ Concentration of standard

Total Protein concentration was carried out using Biuret method as described by Henry et al, (1974). $5 \mathrm{ml}$ of Biuret reagent was pipetted into tubes labeled blank, standard, test, and control respectively. $10 \mathrm{ul}$ of distilled water, standard, sample and control were pipetted and dispensed into the respectively labeled test tubes. All the tubes were mixed and incubated at 250C for 30 minutes. The absorbance ofeach tube was measured at wavelength of $546 \mathrm{~nm}$ against the reagent blank. The concentration of total protein was calculated by dividing the absorbance of sample against absorbance of standard multiplied by concentration of standard.

$$
T P(g / I)=\frac{A T}{A S} x C S
$$

Where TP = Total Protein; AT = Absorbance of Test; $\mathrm{AS}=\mathrm{Absorbance}$ of standard and $\mathrm{CS}=$ Concentration of standard

Albumin estimation was done by Bromocresol green (BCG) method described by Doumas et al. (1971). $3 \mathrm{ml}$ of Bromocresol green reagent was pipette and dispensed into test tubes labeled blank, standard, sample and control respectively. 10ul of distilled water was dispensed into the tube labeled blank while 10ul of standard, sample and control was pipetted into their respectively labelled tubes. The tubes were mixed and incubated at $25^{\circ} \mathrm{C}$ for 5 minutes. The absorbances of each tube contents were measured at wavelength of $578 \mathrm{~nm}$ against the reagent blank. The concentration of Albumin was determined by dividing the absorbance of sample against absorbance of standard multiplied by concentration of standard.

$$
A l b(g / I)=\frac{A T}{A S} x C S \quad 3
$$

$\mathrm{Alb}=$ Albumin, $\mathrm{AT}=$ Absorbance of Test; $\mathrm{AS}=$ Absorbance of standard, $\mathrm{CS}=$ Concentration of standard

Total bilirubin is determined in the presence of caffeine, which releases albumin bound bilirubin, by the reaction which diazotized sulphanillic acid. 200ul of sulphanillic acid was dispensed each into two different test tubes labeled sample blank and sample followed by the addition of 1 drop $(50 \mu l)$ of nitrite reagent and $1000 \mu \mathrm{l}$ of caffeine reagent . $200 \mu \mathrm{l}$ of the test serum was dispensed into each of the test tubes and the mixtures incubated for 10 minutes at $25^{\circ} \mathrm{C}$. This was followed by the addition of $1000 \mu \mathrm{l}$ of tartarate reagent and the mixture incubated again at $25^{\circ} \mathrm{C}$ for 10 minutes. The absorbance of the sample (ATB) was then read against the sample blank at $578 \mathrm{~nm}$ wavelength. The total bilirubin concentration $(\mathrm{mg} / \mathrm{dl})$ was then calculated by multiplying the absorbance of total bilirubin $(578 \mathrm{~nm})$ with 10.8 which is a constant (Jendrassik and Grof 1938).

Total bilirubin $(\mathrm{mg} / \mathrm{dl})=$ Absorbance $\mathrm{x} 10.8$

The serum Direct Bilirubin concentration was determined using the Randox Kit (Randox laboratories limited UK) based on the method described by Jendrassik and Grof, (1938). Direct bilirubin reacts with diazotized sulphanillic acid in alkaline medium to form a blue coloured complex. 200ml of sulphanillic acid was dispensed each into two different test tubes labeled sample blank and sample followed by the addition of 1 drop $(50 \mu \mathrm{l})$ of nitrite reagent and 2000 $\mu \mathrm{l}$ of $0.9 \% \mathrm{NaCl}$. $200 \mu \mathrm{l}$ of the test serum was the dispensed into each of the test tubes and the mixtures incubated for 10 minutes at $25^{\circ} \mathrm{C}$. The absorbance of the sample was then read against the sample blank at $546 \mathrm{~nm}$ wavelength. The direct bilirubin concentration was then calculated by multiplying absorbance of Direct bilirubin (mg/dl) with 14.4 which is a constant. Direct Bilirubin $(\mathrm{mg} / \mathrm{dl})=$ Absorbance $\mathrm{x}$ 14.4... (5)

Quality Control: A Randox normal quality control serum was assayed to determine the precision.

Statistical Analysis: The biochemical data were subjected to statistical analysis groups using Statistical Package for Social Sciences (SPSS) version 18. Values were reported as Mean \pm SEM while student's t-test and analysis of variance (ANOVA) was used to 
test for differences between treatment A value of $\mathrm{P}<0.05$ was accepted as significant.

\section{RESULT AND DISCUSSION}

Table 1 shows the comparison between the mean values of serum total protein $(61.00 \pm 5.16)$, total bilirubin (17.10 \pm 0.50$)$, direct bilirubin $(1.92 \pm 0.50)$, Albumin (35.50 \pm 1.55$)$, AST $(18.50 \pm 0.86)$, ALT $(7.75 \pm 0.25)$, and ALP $(89.78 \pm 5.32)$ in the serum of wistar albino rats administered with graded doses of bark extract of Theobroma cacao with induction.

Table1: Effect of different concentrations of T. cacao on some Liver function indices

\begin{tabular}{|c|c|c|c|c|c|c|c|c|}
\hline \multicolumn{2}{|l|}{ Group } & $\begin{array}{l}\text { Total } \\
\text { Protein } \\
\text { (g/l) }\end{array}$ & $\begin{array}{l}\text { Total } \\
\text { Bilirubin } \\
\text { (umol/l) }\end{array}$ & $\begin{array}{l}\text { Direct } \\
\text { bilirubin } \\
\text { (umol/l) }\end{array}$ & $\begin{array}{l}\operatorname{Albumin}(\mathrm{g} / \mathrm{l} \\
\text { ) }\end{array}$ & $\begin{array}{l}\mathbf{A S T} \\
(\mathbf{U} / \mathbf{L})\end{array}$ & $\begin{array}{l}\mathbf{A L T} \\
(\mathbf{U} / \mathbf{L})\end{array}$ & $\begin{array}{l}\mathbf{A L P} \\
(\mathbf{U} / \mathbf{L})\end{array}$ \\
\hline \multicolumn{2}{|l|}{ Control } & $61.00 \pm 5.16$ & $17.10 \pm 0.50$ & $1.92 \pm 0.07$ & $35.50 \pm 1.55$ & $18.50 \pm 0.86$ & $7.75 \pm 0.25$ & $89.78 \pm 5.32$ \\
\hline \multicolumn{2}{|l|}{ AI } & $58.80 \pm 2.86$ & $23.18 \pm 3.41$ & $2.30 \pm 0.22$ & $28.20 \pm 3.46$ & $43.00 \pm 2.75$ & $5.60 \pm 0.40$ & $102.12 \pm 9.36$ \\
\hline \multicolumn{2}{|c|}{$\mathrm{AI}+100 \mathrm{mgT} . \mathrm{C}$} & $58.50 \pm 10.59$ & $12.90 \pm 1.28$ & $1.47 \pm 0.27$ & $30.00 \pm 3.67$ & $11.75 \pm 3.81$ & $7.25 \pm 0.75$ & $84.39 \pm 15.78$ \\
\hline \multicolumn{2}{|c|}{$\mathrm{AI}+200 \mathrm{mgT} . \mathrm{C}$} & $59.00 \pm 5.65$ & $19.75 \pm 1.56$ & $2.22 \pm 0.16$ & $36.00 \pm 3.08$ & $20.50 \pm 5.12$ & $21.00 \pm 5.32$ & $78.61 \pm 8.05$ \\
\hline \multicolumn{2}{|c|}{$\mathrm{AI}+500 \mathrm{mgT} . \mathrm{C}$} & $61.33 \pm 2.08$ & $19.13 \pm 1.61$ & $1.50 \pm 0.40$ & $27.33 \pm 3.66$ & $7.00 \pm 0.00$ & $8.33 \pm 3.84$ & $77.47 \pm 8.28$ \\
\hline \multicolumn{2}{|c|}{ 200mgT.C } & $53.20 \pm 7.25$ & $20.68 \pm 0.61$ & $2.16 \pm 0.26$ & $29.00 \pm 2.34$ & $18.60 \pm 5.18$ & $9.40 \pm 2.74$ & $77.79 \pm 5.86$ \\
\hline \multicolumn{2}{|c|}{ 500mgT.C } & $67.00 \pm 5.65$ & $12.42 \pm 0.37$ & $0.92 \pm 0.12$ & $32.60 \pm 0.60$ & $8.20 \pm 0.58$ & $11.00 \pm 0.94$ & $68.33 \pm 9.15$ \\
\hline \multicolumn{2}{|c|}{ 1000mg.T.C } & $61.20 \pm 1.78$ & $7.10 \pm 0.40$ & $0.80 \pm 0.08$ & $33.80 \pm 0.58$ & $9.40 \pm 0.40$ & $6.60 \pm 0.24$ & $79.68 \pm 15.01$ \\
\hline \multicolumn{2}{|c|}{$\mathrm{F}$} & 2.183 & 11.644 & 8.595 & 1.665 & 14.551 & 4.396 & 1.010 \\
\hline \multicolumn{2}{|l|}{$\mathrm{P}$} & .068 & .000 & .000 & .160 & .000 & .002 & .446 \\
\hline \multicolumn{9}{|c|}{ POST HOC } \\
\hline \multirow[t]{7}{*}{ Control } & $\mathrm{AI}$ & 1.000 & 0.807 & 0.891 & 0.741 & 0.006 & 0.050 & 0.990 \\
\hline & AI+100mgT.C & 1.000 & 0.327 & 0.870 & 0.939 & 0.814 & 1.000 & 1.000 \\
\hline & AI+200mgT.C & 1.000 & 0.861 & 0.851 & 1.000 & 1.000 & 0.524 & 0.986 \\
\hline & AIt+500mgT.C & 1.000 & 0.959 & 0.981 & 0.686 & 0.008 & 1.000 & 0.963 \\
\hline & 200mgT.C & 0.765 & 0.047 & 0.999 & 0.541 & 1.000 & 1.000 & 0.923 \\
\hline & 500mgT.C & 0.868 & 0.006 & 0.006 & 0.813 & 0.002 & 0.242 & 0.688 \\
\hline & 1000mgT.C & 1.000 & 0.000 & 0.001 & 0.992 & 0.006 & 0.189 & 1.000 \\
\hline \multirow[t]{7}{*}{ AI } & Control & 1.000 & 0.807 & 0.891 & 0.741 & 0.006 & 0.050 & 0.990 \\
\hline & AI+100mgT.C & 1.000 & 0.356 & 0.543 & 1.000 & 0.010 & 0.729 & 0.997 \\
\hline & AI+200mgT.C & 1.000 & 0.999 & 1.000 & 0.860 & 0.146 & 0.405 & 0.754 \\
\hline & AI+500mgT.C & 0.935 & 0.993 & 0.815 & 1.000 & 0.002 & 0.999 & 0.716 \\
\hline & 200mgT.C & 0.879 & 1.000 & 1.000 & 1.000 & 0.082 & 0.943 & 0.595 \\
\hline & 500mgT.C & 0.312 & 0.299 & 0.026 & 0.968 & 0.002 & 0.037 & 0.398 \\
\hline & 500mgT.C & 0.895 & 0.092 & 0.020 & 0.874 & 0.003 & 0.632 & 0.978 \\
\hline \multirow[t]{7}{*}{$\begin{array}{l}\mathrm{AI}+100 \\
\mathrm{mgT} . \mathrm{C}\end{array}$} & Control & 1.000 & 0.327 & 0.870 & 0.939 & 0.814 & 1.000 & 1.000 \\
\hline & $\mathrm{AI}$ & 1.000 & 0.356 & 0.543 & 1.000 & 0.010 & 0.729 & 0.997 \\
\hline & AI+200mgT.C & 1.000 & 0.191 & 0.544 & 0.977 & 0.953 & 0.498 & 1.000 \\
\hline & $\mathrm{AI}+500 \mathrm{mgT} . \mathrm{C}$ & 1.000 & 0.323 & 1.000 & 1.000 & 0.958 & 1.000 & 1.000 \\
\hline & 200mgT.C & 0.999 & 0.048 & 0.803 & 1.000 & 0.996 & 1.000 & 1.000 \\
\hline & 500mgT.C & 0.923 & 1.000 & 0.773 & 1.000 & 0.996 & 0.231 & 0.999 \\
\hline & 1000mgT.C & 1.000 & 0.140 & 0.564 & 0.990 & 1.000 & 0.999 & 1.000 \\
\hline \multirow[t]{7}{*}{$\begin{array}{l}\mathrm{AI}+200 \\
\mathrm{mgT} . \mathrm{C}\end{array}$} & Control & 1.000 & 0.861 & 0.851 & 1.000 & 1.000 & 0.524 & 0.986 \\
\hline & AI & 1.000 & 0.999 & 1.000 & 0.860 & 0.146 & 0.405 & 0.754 \\
\hline & $\mathrm{AI}+100 \mathrm{mgT} . \mathrm{C}$ & 1.000 & 0.191 & 0.544 & 0.977 & 0.953 & 0.498 & 1.000 \\
\hline & $\mathrm{AI}+500 \mathrm{mgT} . \mathrm{C}$ & 1.000 & 1.000 & 0.832 & 0.787 & 0.477 & 0.735 & 1.000 \\
\hline & 200mgT.C & 0.965 & 1.000 & 1.000 & 0.797 & 1.000 & 0.731 & 1.000 \\
\hline & 500mgT.C & 0.645 & 0.131 & 0.012 & 0.985 & 0.557 & 0.764 & 1.000 \\
\hline & 1000mgT.C & 1.000 & 0.026 & 0.011 & 1.000 & 0.641 & 0.457 & 1.000 \\
\hline \multirow[t]{7}{*}{$\begin{array}{l}\mathrm{AI}+500 \\
\mathrm{mgT} . \mathrm{C}\end{array}$} & Control & 1.000 & 0.959 & 0.981 & 0.686 & 0.008 & 1.000 & 0.963 \\
\hline & AI & 0.935 & 0.993 & 0.815 & 1.000 & 0.002 & 0.999 & 0.716 \\
\hline & AI+100mgT.C & 1.000 & 0.323 & 1.000 & 1.000 & 0.958 & 1.000 & 1.000 \\
\hline & AI+200mgT.C & 1.000 & 1.000 & 0.832 & 0.787 & 0.477 & 0.735 & 1.000 \\
\hline & 200mgT.C & 0.538 & 0.995 & 0.938 & 1.000 & 0.598 & 1.000 & 1.000 \\
\hline & 500mgT.C & 0.690 & 0.258 & 0.919 & 0.901 & 0.676 & 1.000 & 1.000 \\
\hline & 1000mgT.C & 1.000 & 0.080 & 0.816 & 0.798 & 0.042 & 1.000 & 1.000 \\
\hline $\begin{array}{l}\text { 200mg } \\
\text { T.C }\end{array}$ & CTL & 0.765 & 0.047 & 0.999 & 0.541 & 1.000 & 1.000 & 0.923 \\
\hline & $\mathrm{AI}$ & 0.879 & 1.000 & 1.000 & 1.000 & 0.082 & 0.943 & 0.595 \\
\hline & AI+100mgT.C & 0.999 & 0.048 & 0.803 & 1.000 & 0.996 & 1.000 & 1.000 \\
\hline & $\mathrm{AI}+200 \mathrm{mgT} . \mathrm{C}$ & 0.965 & 1.000 & 1.000 & 0.797 & 1.000 & 0.731 & 1.000 \\
\hline & $\mathrm{AI}+500 \mathrm{mgT} . \mathrm{C}$ & 0.538 & 0.995 & 0.938 & 1.000 & 0.598 & 1.000 & 1.000 \\
\hline & 500mgT.C & 0.162 & 0.000 & 0.079 & 0.913 & 0.704 & 1.000 & 1.000 \\
\hline & 1000mgT.C & 0.527 & 0.000 & 0.058 & 0.708 & 0.802 & 0.994 & 1.000 \\
\hline $\begin{array}{l}500 \mathrm{mg} \\
\text { T.C }\end{array}$ & CTL & 0.868 & 0.006 & 0.006 & 0.813 & 0.002 & 0.242 & 0.688 \\
\hline & $\mathrm{AI}$ & 0.312 & 0.299 & 0.026 & 0.968 & 0.002 & 0.037 & 0.398 \\
\hline
\end{tabular}

GEORGE-OPUDA, IM; ADEGOKE, OA; OLUWATAYO, OB; ODEGHE, OB; NDIBE, $J$ 


\begin{tabular}{|c|c|c|c|c|c|c|c|c|}
\hline & AI+100mgT.C & 0.923 & 1.000 & 0.773 & 1.000 & 0.996 & 0.231 & 0.999 \\
\hline & $\mathrm{AI}+200 \mathrm{mgT} . \mathrm{C}$ & 0.645 & 0.131 & 0.012 & 0.985 & 0.557 & 0.764 & 1.000 \\
\hline & $\mathrm{AI}+500 \mathrm{mgT} . \mathrm{C}$ & 0.690 & 0.258 & 0.919 & 0.901 & 0.676 & 1.000 & 1.000 \\
\hline & 200mgT.C & 0.162 & 0.000 & 0.079 & 0.913 & 0.704 & 1.000 & 1.000 \\
\hline & 100mgT.C & 0.614 & 0.000 & 1.000 & 0.950 & 0.854 & 0.092 & 1.000 \\
\hline $\begin{array}{l}1000 \mathrm{mg} \\
\text { T.C }\end{array}$ & CTL & 1.000 & 0.000 & 0.001 & 0.992 & 0.006 & 0.189 & 1.000 \\
\hline & $\mathrm{AI}$ & 0.895 & 0.092 & 0.020 & 0.874 & 0.003 & 0.632 & 0.978 \\
\hline & $\mathrm{AI}+100 \mathrm{mgT} . \mathrm{C}$ & 1.000 & 0.140 & 0.564 & 0.990 & 1.000 & 0.999 & 1.000 \\
\hline & $\mathrm{AI}+200 \mathrm{mgT} . \mathrm{C}$ & 1.000 & 0.026 & 0.011 & 1.000 & 0.641 & 0.457 & 1.000 \\
\hline & $\mathrm{AI}+500 \mathrm{mgT} . \mathrm{C}$ & 1.000 & 0.080 & 0.816 & 0.798 & 0.042 & 1.000 & 1.000 \\
\hline & 200mgT.C & 0.527 & 0.000 & 0.058 & 0.708 & 0.802 & 0.994 & 1.000 \\
\hline & 500mgT.C & 0.614 & 0.000 & 1.000 & 0.950 & 0.854 & 0.092 & 1.000 \\
\hline
\end{tabular}

There was significant decreases $(p<0.05)$ of total bilirubin, direct bilirubin and AST in the serum of untreated and treated $(500 \mathrm{mg} \mathrm{T}$. Cacao) group when compared with the normal group. All the groups treated with the extract doses $(200,500,1000$ $\mathrm{mg} / \mathrm{kgb} . \mathrm{w})$ showed significant reduction $(p<0.05)$ in total bilirubin, direct bilirubin and AST when compared with the untreated group. However, no significant change $(p>0.05)$ was observed in the serum total protein, ALT and ALP in the test when compared with the control. The result of the study showed that there was significant difference in the total bilirubin and direct bilirubin concentration as well as AST and ALT activities of T cacao treated at different concentrations compared with their respective controls. The marker enzymes assayed in the $T$ cacao groups showed dose dependent decrease in enzyme activity. Phytochemicals are a large group of plant-derived compounds hypothesised to be responsible for much of the disease protection conferred from diets high in fruits, vegetables, beans, cereals, and plant-based beverages such as tea and wine (Arts, and Hollman, 2005). Bilirubin is the main bile pigment that is formed from the breakdown of haemoglobin in the red blood cells. It is transported to the liver where it is secreted by the liver into the bile. Table 2 shows the comparison between the mean values of serum total protein $(61.00 \pm 5.16)$, total bilirubin (17.10 \pm 0.50$)$, direct bilirubin $(1.92 \pm 0.50)$, Albumin (35.50 \pm 1.55$)$, AST (18.50 \pm 0.86$)$, ALT (7.75 \pm 0.25$)$, and ALP (89.78 \pm 5.32$)$ in the serum of wistar albino rats administered with graded doses of bark extract of Theobroma cacao with induction. There was significant decreases $(p<0.05)$ of total bilirubin, direct bilirubin and AST in the serum of untreated and treated $(500 \mathrm{mg}$ T. Cacao) group when compared with the normal group. All the groups treated with the extract doses $(200,500,1000$ $\mathrm{mg} / \mathrm{kgb} . \mathrm{w})$ showed significant reduction $(p<0.05)$ in total bilirubin, direct bilirubin and AST when compared with the untreated group. However, no significant change $(p>0.05)$ was observed in the serum total protein, ALT and ALP in the test when compared with the control. The result of the study showed that $T$ cacao caused significant reduction in Total bilirubin, Total protein concentration as well as activity of AST.

Table 2 Effect of $T$ cacao on Liver indices

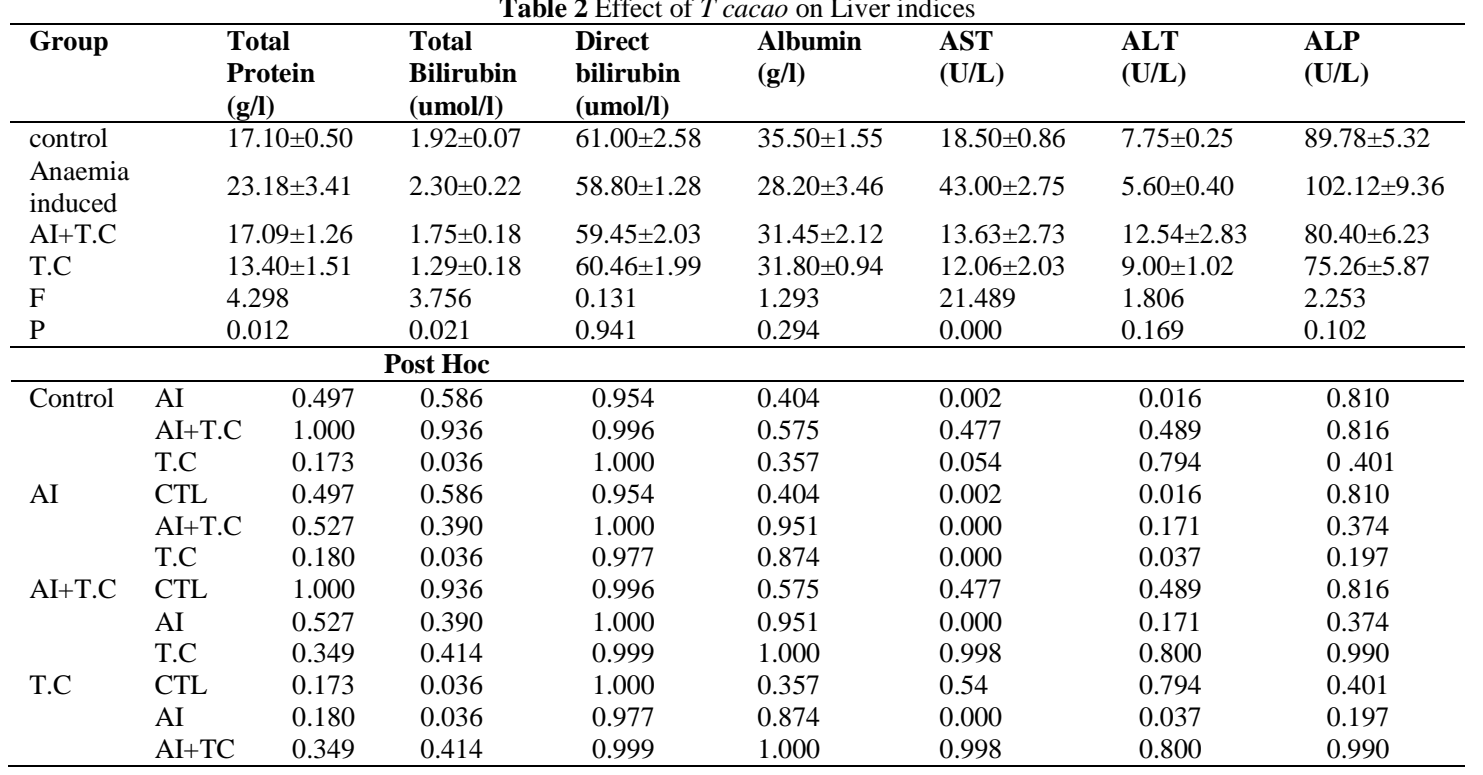


The result further showed that there was increase in AST, ALT activities in anaemia induced compared with their respective control which may be due to leakage from hepatocytes through peroxidative damage of their membranes by anaemic induction. The increase in Total bilirubin as seen in the study may be as result of cellular damage causing elevated Total bilirubin. The increase in bilirubin level of phenylhydrazine-induced animals, may be as a result of increase in the oxidative break down of red blood cells by phenylhrdrazine. The total proteins include albumin and globulins. Test for total protein in blood is often done to diagnose nutritional problems, kidney disease or liver disease. Albumin which is produced only in the liver is the major plasma protein that circulates in the blood stream. It helps move many small molecules through the blood, including bilirubin, calcium, progesterone, and medications. Albumin also plays an important role in keeping the fluid from the blood from leaking out into the tissues. Increased albumin content in the normal animals receiving $100 \mathrm{mg} / \mathrm{Kg}$ compared to the normal control animal may be due to high protein content of their diet and/or extract. The significant $(\mathrm{P}>0.05)$ increase in the level of albumin may indicate that the synthetic function of the liver has not been significantly affected yet, since albumin is synthesized only in the liver.

Conclusion: The result of the study showed that $T$ cacao reversed changes caused by Phenylhydrazine on some Liver parameters.

\section{REFERENCES}

Agarwal, SK. (2013). Dark chocolate: a therapeutic food. Medical Science, 1(1): 13-15.

Alamu, SA. (2013). Analysis of seedling subsidy policy and cocoa production south-west Nigeria. Nigerian Institute of Social and Economic Research, 3(4):

Arts, ICW; Hollman, PCH. (2005). Polyphenols and disease risk in epidemiologic study The American Journal of Clinical Nutrition, 81(1): 317-325.

Babson, LA; Greeley, SJ; Coleman, CM.,Philips, GD. (1966). Phenolphthalein monophosphate as a substrate for serum alkaline phosphatase. Clinical Chemistry, 12: $482-490$.

Dede, EB; Igboh, NM; Ayalogu, OE.(2001). Acute toxicity of crude petroleum (Bonny light) kerosene and gasoline in albino rats. J. Appl. Sci. Environ. Manage. 5 (2): 73 - 55.
Doumas, BT; Watson, WA; Biggs, HG (1971).Albumin standards and the measurement of serum albumin with Bromocresol green. Clinical Chemistry Acta; 31:87.

Henry, R J; Cannon, DC; Winkelman, JW.(1974). Clinical Chemistry Principles and Techniques, Harper and Row $2^{\text {nd }}$ Edition.

Jendrassik, L; Grof, P. (1938). Estimation of total serum bilirubin level by spectrophotometrically in serum and plasma. BiochemZeitschrift, 297: 8189.

Reitman, S; Frankel, SA (1957). Colorimetric method for determination of serum glutamic oxaloacetic transaminase (SGOT) and serum glutamic pyruvic transaminase (SGPT). Am. J. Clinical Path. 28: 56.

Rona, G; Chappel, CT; Balaz, T; Gaudry, R. (1959). An infarct like myocardial lesion and other true manifestation produced by isoproterenol in the rat. Arch Pathol 67, 433-55.

Schinella G; Mosca S; Cienfuegos-Jovellanos E; Pasamar M.A; Muguerza B; Ramon D; Rios J.L. (2010). Anti-oxidant properties of polyphenolrich cocoa products industrially processed. Food Res. Int; 43:1614-1623.

Seth, SD; Maulik, M; Katiyar, CK; Maulik, SK. (1998). Role of lipistat in protection against isoproterenol induced myocardial necrosis in rats: a biochemical and histological study. Ind $J$ Physiol. Pharmacol. 42, 101-6.

Velioglu, YS; Mazza, G; Gao, L; Oomah. BD. (1998). Antioxidant activity and total phenolics in selected fruits, vegetables, and grain products. .J. Agric. Food Chem. 46:4113-4117.

Zimmerman, HJ. (1974). Serum enzymes measurement in experiment hepatotoxicity In: International Symposium on hepatotoxicity (Elikan, M., Eschar, J. and Zimmerman, H. J. (Eds). Academic Press, New York 